University of Nebraska - Lincoln

DigitalCommons@University of Nebraska - Lincoln

1988

\title{
Size differences in migrant sandpiper flocks: ghosts in ephemeral guilds
}

Jan L. Eldridge

Bell Museum of Natural History

Douglas $\mathrm{H}$. Johnson

USGS Northern Prairie Wildlife Research Center, Douglas_H_Johnson@usgs.gov

Follow this and additional works at: https://digitalcommons.unl.edu/usgsnpwrc

Part of the Other International and Area Studies Commons

Eldridge, Jan L. and Johnson, Douglas H., "Size differences in migrant sandpiper flocks: ghosts in ephemeral guilds" (1988). USGS Northern Prairie Wildlife Research Center. 237.

https://digitalcommons.unl.edu/usgsnpwrc/237

This Article is brought to you for free and open access by the US Geological Survey at DigitalCommons@University of Nebraska - Lincoln. It has been accepted for inclusion in USGS Northern Prairie Wildlife Research Center by an authorized administrator of DigitalCommons@University of Nebraska - Lincoln. 


\title{
Original papers
}

\section{Size differences in migrant sandpiper flocks: ghosts in ephemeral guilds}

\author{
Jan L. Eldridge ${ }^{1, *}$ and Douglas H. Johnson ${ }^{2}$ \\ ${ }^{1}$ University of Minnesota, Department of Ecology and Behavioral Biology, Bell Museum of Natural History, \\ 10 Church Street S.E., Minneapolis, MN 55455, USA \\ ${ }^{2}$ U.S. Fish and Wildlife Service, Northern Prairie Wildlife Research Center, P.O. Box 2096, Jamestown, ND 58402, USA
}

\begin{abstract}
Summary. Scolopacid sandpipers were studied from 1980 until 1984 during spring migration in North Dakota. Common species foraging together in mixed-species flocks differed in bill length most often by 20 to 30 percent (ratios from 1.2:1 to 1.3:1). Observed flocks were compared to computer generated flocks drawn from three source pools of Arctic-nesting sandpipers. The source pools included 51 migrant species from a global pool, 33 migrant species from a Western Hemisphere pool, and 13 species that migrated though North Dakota. The observed flocks formed randomly from the available species that used the North Dakota migration corridor but the North Dakota species were not a random selection from the Western Hemisphere and global pools of Arctic-nesting scolopacid sandpipers. In short, the ephemeral, mixed-species foraging flocks that we observed in North Dakota were random mixes from a nonrandom pool. The size-ratio distributions were consistent with the interpretation that use of this migration corridor by sandpipers has been influenced by some form of sizerelated selection such as competition.
\end{abstract}

Key words: Size ratio - Shorebirds - Migration - Null models - Competition

Many sandpiper species in the family Scolopacidae migrate to the Arctic from the southern regions of South America, Africa, and Australasia (Hayman et al. 1986). During migration they forage for invertebrates in open, shallow-water habitats, often in mixed-species flocks. Sandpipers may in fact depend on food resources obtained during migration to reproduce successfully in the Arctic (MacLean 1969; Ashkenazie and Safriel 1979). These food resources appear to be limited and depletable (Schneider and Harrington 1981). Competition for limited resources among migrant sandpipers has been used to explain a variety of phenomena including absence of some species in a migration corridor (Recher 1966), aggression within mixed-species flocks (Recher and Recher 1969), timing of migration (Recher 1966; Myers 1981), and differences in mating systems (Myers 1981).

If competition is a significant force in a community, certain patterns should occur; for example, a close relationship should exist between morphology and the limiting re-

* Present address and address for offprint requests: Minnesota Valley NWR, 4101 E. 80th Street, Bloomington, MN 55425, USA source (Schoener 1965; Grant 1967; Hespenheide 1973; Wiens 1984) and coexisting species should differ in size by at least a minimum amount (see reviews by Carothers 1986 and Schoener 1986).

A close relationship among morphology, foraging water depth, and invertebrate food size has been demonstrated among Arctic-nesting sandpipers during migration (Eldridge and $\mathrm{Krapu}$, in prep.). The purpose of this paper is to determine if a minimum size difference occurs among sandpipers that associate during migration in North Dakota. The null hypothesis is that species of sandpipers associate by chance during migration.

Because the shallow wetlands used by shorebirds in North Dakota are islands of habitat in an extensive "archipelago" of wetlands known as the Prairie Pothole Region (Stewart and Kantrud 1971), asking if sandpipers associate randomly is analogous to asking if species assemble by chance on island archipelagoes (Connor and Simberloff 1979; Alatalo 1982; Harvey et al.1983; Strong et al. 1984). However, unlike island communities where species colonize and breed, the mixed-species flocks of foraging sandpipers are temporary gatherings, ephemeral guilds enroute to Arctic breeding grounds. A global perspective may be more appropriate for this highly migratory group of species, and a better focus for community interaction may be the migration corridor, rather than the individual flock. Recher and Recher (1969) suggested that interspecific competition inhibited very similar species from using the same migration route, thereby implying that the community is the group of species using a migration corridor.

In this paper we ask if the species in the mixed-species flocks we observed are a random selection from the pool of species that commonly pass through North Dakota during migration. We then determine if the species that migrate through North Dakota are a random selection from the global or Western Hemisphere pools of Arctic-nesting sandpipers.

\section{Methods}

\section{Flock observations}

Flocks of migrant shorebirds were observed from mid-April through June, 1980-1984, in Stutsman and Kidder counties of North Dakota. "Flocks" refer to birds observed within a 10-meter diameter circle of foraging habitat; as a result, each flock represents bird density in a comparable area. 
The species composition of each flock was recorded after watching birds forage for $10 \mathrm{~min}$. Most flock observations were from different wetlands but some wetlands were observed several days apart. We considered observations from the same wetland to be independent because flock composition changed rapidly from day to day during the study period.

\section{Size measure}

We used bill length as the measure of size, because bill length has been correlated with prey size in sympatric sandpipers in the Arctic (Holmes and Pitelka 1968). In the most common species of shorebirds migrating through North Dakota, bill length is a better predictor of prey size than is tarsus length, body length, or body mass (Eldridge and $\mathrm{Krapu}$, unpublished work). For North Dakota specimens we measured bill length following the technique in Prater et al. (1977). These specimens were collected for dietary analysis as reported in Eldridge and Krapu (unpublished work). For other species we used measurements from Prater et al. (1977). Following Schoener's (1984) rationale, we used average size for a species, choosing to ignore sexual dimorphism and geographic variation (Appendix A).

\section{Source pools}

We used Schoener's (1984) technique to investigate sizerelated patterns of association. This technique involved drawing species combinations from a global source pool of species to simulate random associations. Distributions of size ratios from the random associations were then compared with distributions observed in actual species associations. Schoener used Hutchinsonian size ratios (Hutchinson 1959) in which the larger species measurement was divided by that of the smaller species. The key to his technique was the use of a global source pool of species for his null model and that he considered the entire distribution of ratios rather than the average ratio from the distribution (cf., Eadie et al. 1987) or a single common ratio within the distribution (see references in Simberloff and Boecklen 1981).

The source pools used in our analysis were ordered subsets from a global pool of Arctic-nesting sandpipers with successive subsets more similar to the observed flocks (Appendix $A)$. The global source pool $(G)$ included 51 species considered northern Holarctic, Nearctic or Palaearctic breeders by Prater et al. (1977). The Western Hemisphere source pool (WH) contained 33 species that migrate through the Western Hemisphere to nest in the Arctic. The North Dakota source pool (ND) was limited to 13 species that were actually observed in flocks during this study, although other sandpiper species occasionally migrate through North Dakota. The North Dakota source pool represents the common species that use the migration corridor through North Dakota.

We constrained the North Dakota source pool further in the weighted North Dakota source pool (Wt.ND). The weighting factor accounts for differing abundances of species and represents the probability of a given flock occurring if species associate independently. We determined, $p_{i}$, the probability of occurrence in a flock for species $i$, by counting the number of flocks in which species $i$ was present and dividing by the total number of flocks observed (Table 1). Next, we looked at all possible flocks that could be generated with the 13 North Dakota species.
Table 1. The probability of occurrence of migrant sandpiper species in observed flocks in shallow-water feeding habitat of North Dakota

\begin{tabular}{ll}
\hline Species & Probability \\
\hline Semipalmated Sandpiper, Calidris pusilla & 0.3965 \\
White-rumped Sandpiper, Calidris fuscicollis & 0.3864 \\
Baird's Sandpiper, Calidris bairdii & 0.3535 \\
Pectoral Sandpiper, Calidris melanotos & 0.1742 \\
Least Sandpiper, Calidris minutilla & 0.1465 \\
Lesser Yellowlegs, Tringa flavipes & 0.1162 \\
Stilt Sandpiper, Calidris himantopus & 0.0934 \\
Dunlin, Calidris alpina & 0.0758 \\
Long-billed Dowitcher, Limnodromus scolopaceus & 0.0429 \\
Sanderling, Calidris alba & 0.0379 \\
Solitary Sandpiper, Tringa solitaria & 0.0301 \\
Greater Yellowlegs, Tringa melanoleuca & 0.0278 \\
Western Sandpiper, Calidris mauri & 0.0025 \\
\hline
\end{tabular}

The weighting factor for each possible flock was determined by multiplying the probabilities of species presence or absence for all 13 North Dakota species as follows:

$W=\prod_{i=1}^{13} p_{i}^{\delta_{i}}\left(1-p_{i}\right)^{1-\delta_{i}}$

where:

$p_{i}=\operatorname{prob}\{$ species $i$ is present $\}$

$\delta_{i}=\left\{\begin{array}{l}1 \text { if species } i \text { is present } \\ 0 \text { if not }\end{array}\right\}$

\section{Expected mixed-species flocks}

We generated "expected" mixed-species flocks by picking all possible combinations of two, three, and four species (or random selections thereof) from each source pool. From the global pool, we considered all 1275 two-species flocks and 1000 randomly selected three- and four-species flocks. From the Western Hemisphere pool, we considered all 528 two-species flocks and 1000 randomly selected three- and four-species flocks. We randomly selected 1000 three- and four-species flocks from the global and Western Hemisphere pools because the data sets were so large. From the North Dakota and weighted North Dakota source pools, the analysis included 78 two-species flocks, 286 threespecies flocks, and 715 four-species flocks.

\section{Bill-size ratios}

Bill-size ratios were computed in the same way for both observed and expected flocks. We ordered the constituent species of each observed or expected mixed-species flock by bill size and computed Hutchinsonian ratios (larger bill size divided by the smaller size, Hutchinson 1959) from bill sizes of adjacent species. We separated the resulting ratio distributions; two-species flocks had one ratio distribution (Sp1/Sp2, where Sp1 was the bill measurement of the larger species), three-species flocks had two ratio distributions (Sp1/Sp2, Sp2/Sp3), and four-species flocks had three ratio distributions (Sp1/Sp2, Sp2/Sp3, Sp3/Sp4).

Expected or "null" distributions of bill-size ratios were compared with observed distributions using the Kolmogorov-Smirnov cumulative frequency test, modified for sample size as outlined by Sokal and Rohlf (1981). 


\section{Test criteria}

We used Schoener's (1984) approach to create expected ratio distributions, but we used Tonkyn and Cole's (1986) theoretical analysis to distinguish patterns in the size-ratio distributions. Tonkyn and Cole (1986) found that the sizeratio distributions generated under the null model that species coexist independently of size are shaped differently than ratio distributions from species pools where competition has influenced species associations. Null ratio distributions for the former have histograms that 1) decrease monotonically from a peak at size ratio $1.0,2$ ) are concave, and 3 ) have average ratio values that decrease as guild size increases.

In contrast, ratio distributions from guilds structured by competition are neither monotonically declining nor concave but unimodal, peaking, for example, between 1.2 and 1.3. In addition, as guild size increases, average ratios hold constant or increase due to diffuse competition (Pianka 1974; Tonkyn and Cole 1986).

\section{Results}

\section{Observed flocks}

During the study, 314 flocks involving 13 migrating sandpiper species were observed (Table 1). Most flocks $(66 \%)$ were mixed-species flocks containing up to six species in a variety of species combinations (Appendix B). The analyses were based on 84 two-species flocks, 57 three-species flocks, and 39 four-species flocks. Too few five- or sixspecies flocks (18 and 8 , respectively) were observed to be included.

Test 1: Underlying bill-size distributions of source pools We compared the bill-size distributions of the source pools and determined that they were asymmetrical and roughly log-normal in shape as predicted by Schoener (1984) (Fig. 1). The bill-size distributions did not differ between successive source pools (Kolmogorov-Smirnov test: global to Western Hemisphere comparison, $\mathrm{D}=0.0446, P>0.05$; Western Hemisphere to North Dakota comparison, $\mathrm{D}=0.1048, P>$ 0.05). As a result, each source pool could be considered a subset with the probability of selection unrelated to bill size.

Test 2: Comparing expected ratio distributions

Because the three primary source pools were subsets (Test 1), we were able to compare ratio distributions (global to Western Hemisphere, Western Hemisphere to North Dakota, and North Dakota to weighted North Dakota source pools). In most comparisons, size-ratio distributions from global and Western Hemisphere source pools did not differ but Western Hemisphere and North Dakota size-ratio distributions did differ (Table 2).

The differences between source pool distributions were revealed in the shape of their histograms (Figs. 2 and 3). In the transition from global to North Dakota source pools, the ratio distributions changed shape from monotonically declining and concave to unimodal, peaking at ratios from 1.2 to $1.3(1.2 \leq r<1.3)$. Following Tonkyn and Cole's (1986) criteria, associations from the global pool appeared independent of bill size, but associations from the North Dakota pool were nonrandom with respect to bill size.
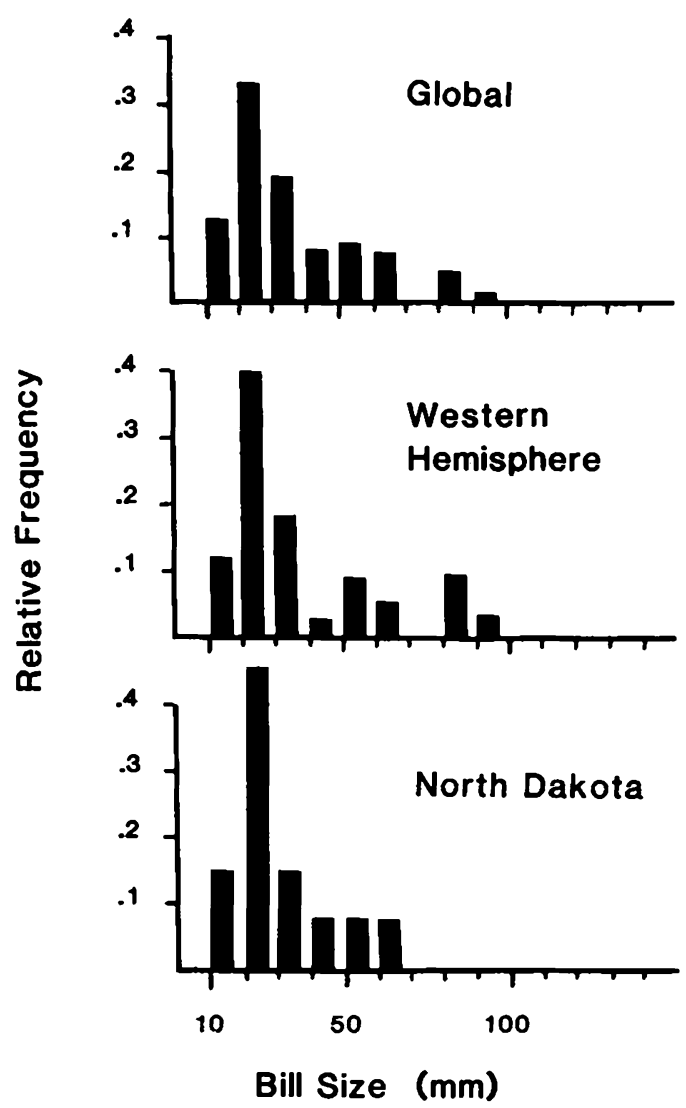

Fig. 1. Each source pool of sandpipers has an asymmetrical and roughly log-normal bill-size distribution

Table 2. A comparison of distributions of bill-size ratios drawn from four source pools of migrant sandpipers: global $(G)$, Western Hemisphere (WH), North Dakota (ND), and weighted North Dakota (Wt. ND) ${ }^{a}$

\begin{tabular}{|c|c|c|c|c|c|c|c|}
\hline \multirow[b]{3}{*}{ Flock size } & \multirow[b]{3}{*}{ Ratio } & \multicolumn{6}{|c|}{ Source Pool Comparisons } \\
\hline & & \multicolumn{2}{|l|}{ G-WH } & \multicolumn{2}{|c|}{ WH-ND } & \multicolumn{2}{|c|}{ ND-Wt.ND } \\
\hline & & D & $P$ & $\mathrm{D}$ & $P$ & D & $P$ \\
\hline 2-Species & $\mathrm{Sp} 1 / \mathrm{Sp} 2$ & 0.0464 & NS & 0.1363 & NS & 0.2720 & 0.01 \\
\hline 3-Species & $\begin{array}{l}\mathrm{Sp} 1 / \mathrm{Sp} 2 \\
\mathrm{Sp} 2 / \mathrm{Sp} 3\end{array}$ & $\begin{array}{l}0.0410 \\
0.0440\end{array}$ & $\begin{array}{l}\text { NS } \\
\text { NS }\end{array}$ & $\begin{array}{l}0.1502 \\
0.1766\end{array}$ & $\begin{array}{l}0.01 \\
0.01\end{array}$ & $\begin{array}{l}0.1624 \\
0.2806\end{array}$ & $\begin{array}{l}0.01 \\
0.01\end{array}$ \\
\hline 4-Species & $\begin{array}{l}\text { Sp1/Sp2 } \\
\text { Sp2/Sp3 } \\
\text { Sp3/Sp4 }\end{array}$ & $\begin{array}{l}0.0750 \\
0.0470 \\
0.1020\end{array}$ & $\begin{array}{l}0.01 \\
\text { NS } \\
0.01\end{array}$ & $\begin{array}{l}0.1287 \\
0.1724 \\
0.1202\end{array}$ & $\begin{array}{l}0.01 \\
0.01 \\
0.01\end{array}$ & $\begin{array}{l}0.1055 \\
0.1761 \\
0.2761\end{array}$ & $\begin{array}{l}0.01 \\
0.01 \\
0.01\end{array}$ \\
\hline
\end{tabular}

all comparisons use Kolmogorov-Smirnov maximum difference, $\mathrm{D}$, of cumulative frequencies $(\mathrm{NS}=P>0.05$ )

The North Dakota source pool represents the common species that use the migration corridor through North Dakota and the ratio distributions were based on recombinations of species actually observed in mixed-species flocks. When compared with the global and Western Hemisphere distributions, ratio distributions from the 13 species observed in mixed-species flocks in North Dakota differed more in size than expected and the shape of the distribution fits Tonkyn and Cole's (1986) criteria for species associations that are influenced by interspecific competition. 
A Relative Frequency

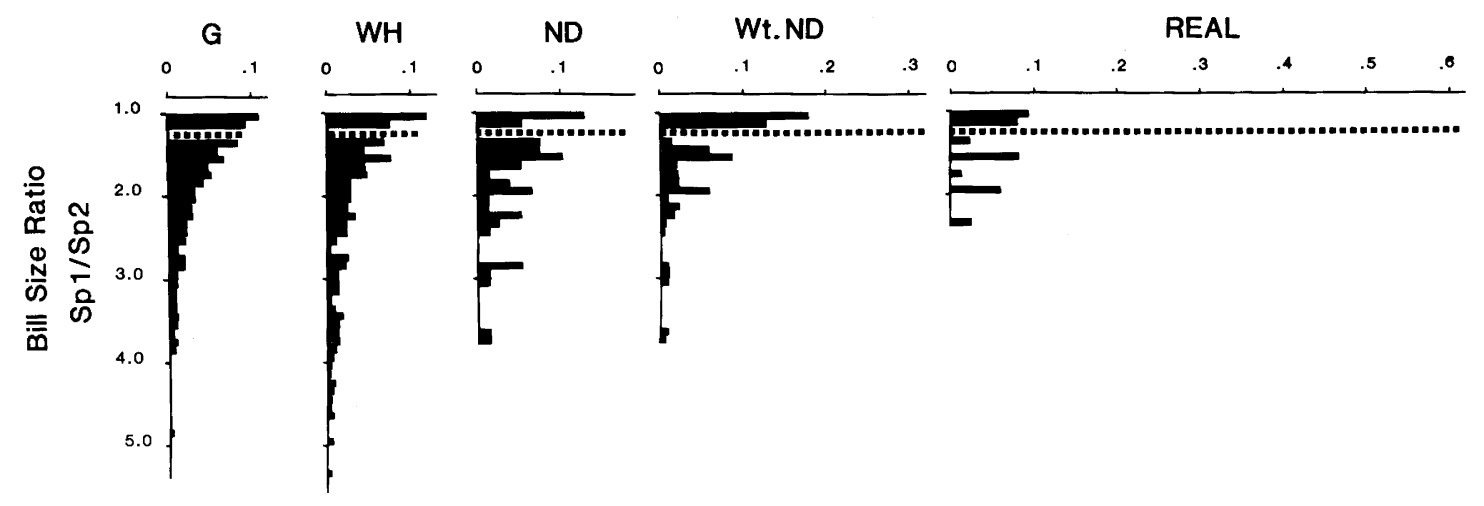

B

Relative Frequency

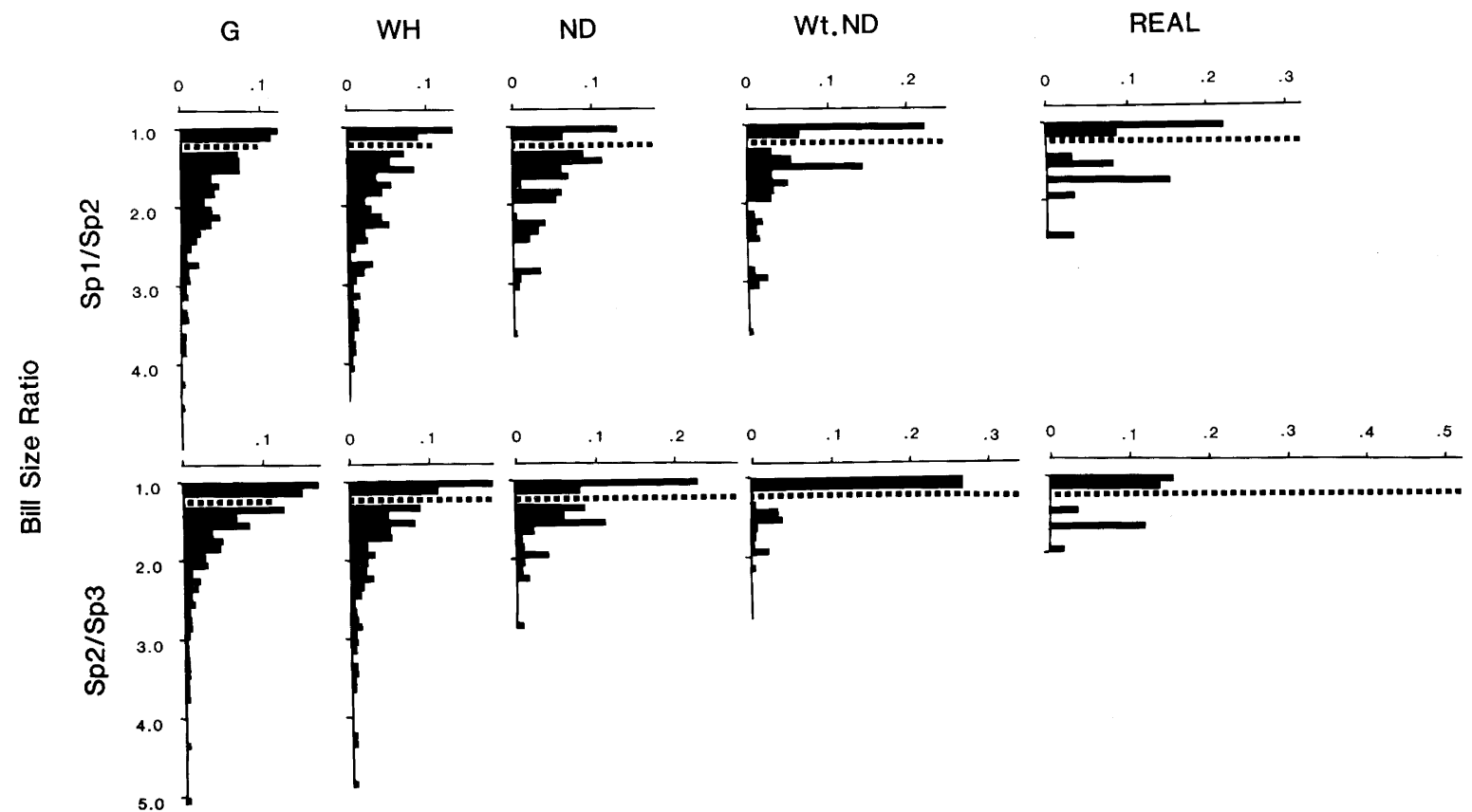

Fig. 2 A, B. Bill-size ratio distributions of sandpiper flocks from global $(G)$, Western Hemisphere $(W H)$, North Dakota $(N D)$, and weighted North Dakota $(W t . N D)$ source pools and observed $(R E A L)$ flocks. The dashed bar represents ratios, $r$, where $1.2 \leq r<1.3$. A, Pairs have one ratio distribution, $\mathrm{Sp} 1 / \mathrm{Sp} 2$ and $\mathbf{B}$, Trios have two ratios, $\mathrm{Sp} 1 / \mathrm{Sp} 2, \mathrm{Sp} 2 / \mathrm{Sp} 3$

Weighting the North Dakota source pool with the actual probability of occurrence for each species increased the relative frequency of ratios ranging from 1.2 to 1.3 . In all comparisons, weighted ratio distributions differed from unweighted North Dakota ratio distributions (Table 2). This means that the 13 North Dakota species were not a random selection from the Western Hemisphere source pool and the difference was magnified by considering the relative abundance of species in the migration corridor.

Test 3: Simulations of 13-species source pools

In this analysis flocks generated from the North Dakota weighted and unweighted source pools resulted in ratio distributions that did not meet Tonkyn and Cole's (1986) criteria for random assortment, but Tonkyn and Cole's analysis was based on an infinite number of species. It is possible that the North Dakota pools, with only 13 species, were too small for Tonkyn and Cole's conclusions to apply.
We addressed this problem by creating 100 source pools of 13 species each, drawn randomly from the global pool. For each pool we generated all possible two-species flocks (13 species taken two at a time results in 78 flocks), computed the bill-size ratio for each pair (larger species over smaller), and determined the ratio frequencies (for ratio categories, $r_{i}$, where $1.0 \leq r_{1}<1.1$, etc.). We then had a set of 100 histograms of ratio distributions that were comparable to the North Dakota histogram for ratios from twospecies flocks and we obtained a sample distribution of the mean and standard deviation for each ratio category.

As we simulated each source pool we also randomly attached to each species a probability of occurring in a flock and we used the weighting factor as before (equation 1) to obtain a weighted ratio distribution for two-species flocks. We then computed a sample distribution with mean and standard deviation for each ratio category from the 100 weighted ratio distributions. 


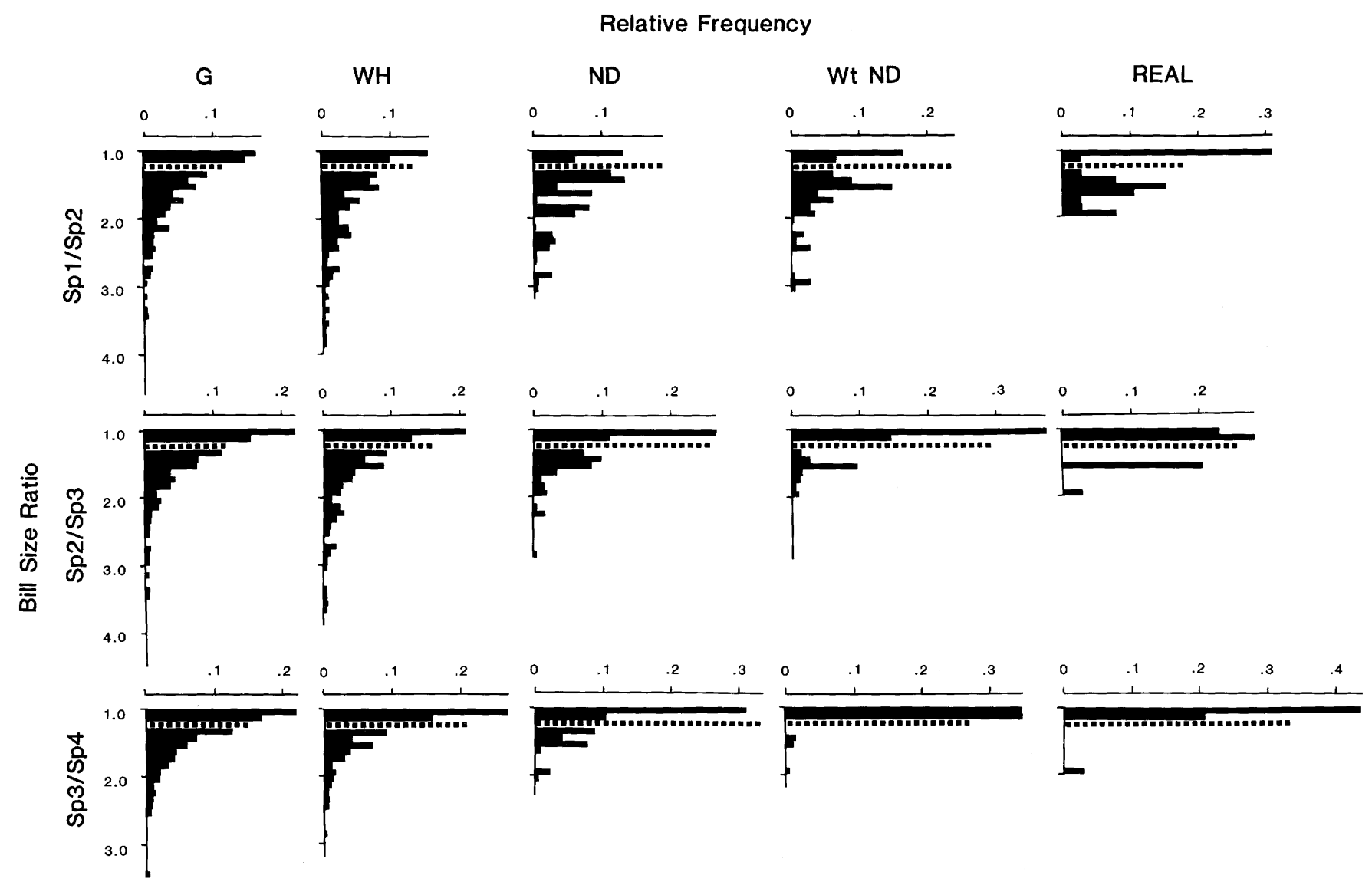

Fig. 3. Bill-size ratio distributions of sandpipers from global $(G)$, Western Hemisphere $(W H)$, North Dakota $(N D)$, and weighted North Dakota $(W t . N D)$ source pools and observed $(R E A L)$ flocks. The dashed bar represents ratios, $r$, where $1.2 \leq r<1.3$. Four-species flocks have three ratio distributions, $\mathrm{Sp} 1 / \mathrm{Sp} 2, \mathrm{Sp} 2 / \mathrm{Sp} 3, \mathrm{Sp} 3 / \mathrm{Sp} 4$

Both weighted and unweighted sample distributions were monotonically declining and concave compared to the unimodal histograms for two-species flocks from the North Dakota unweighted and weighted source pools (Fig. 4). The frequency of ratios in the North Dakota histograms that were in the category of 1.2 to 1.3 exceeded the mean and standard deviation of the random simulations. We conclude that the species that migrate through North Dakota do not represent a random selection from the global pool.

\section{Test 4: Comparing expected and observed ratio} distributions

We asked if the ratio distributions of observed flocks (Real distributions) differed from the expected ratio distributions of all source pools. The observed ratio distributions differed from most global, Western Hemisphere, and North Dakota source pool distributions, but not from the weighted North Dakota source pool distributions (Table 3). The shape of the histograms from observed flocks revealed an increase in the relative dominance of size ratios 1.2 to 1.3 when compared with the histograms from North Dakota and weighted North Dakota ratio distributions (Fig. 2) for all but four-species flocks where the dominance was not evident (Fig. 3).

We conclude that for two- and three-species flocks, the shape of the observed ratio distributions can be explained by the set of species migrating through North Dakota and their relative probabilities of occurrence. The results for four-species flocks were ambiguous.

\section{Test 5: Two most abundant species from each flock}

We asked if relative abundance within flocks might, in part, explain the absence in four-species flocks of the trend observed in two- and three-species flocks. The usual method for determining Hutchinsonian ratios ignores individual abundance within guilds (flocks). If a flock consists of two abundant species, Sp1 and Sp3, separated in size by a single individual of a third species, $\mathrm{Sp} 2$, the usual method will overemphasize the middle species by including it in both ratios (Sp1/Sp2 and $\mathrm{Sp} 2 / \mathrm{Sp} 3$ ). This background "noise" will increase with flock size and may obscure trends between abundant species in the flock.

We considered ratio distributions for three- and fourspecies flocks calculated solely with the two most abundant species in each flock (2-Real distributions). The resulting ratio distributions were unimodal, peaking at ratios of 1.2 to 1.3 , and were indistinguishable from the ratio distribution of observed two-species flocks (Fig. 5A). Distributions calculated using only the two most abundant species in three- and four-species flocks differed from the weighted North Dakota distributions for three- and four-species flocks and from the observed distributions for four-species flocks (Table 4). We conclude that the trend of ratios peaking at 1.2 to 1.3 exists in observed four-species flocks just 

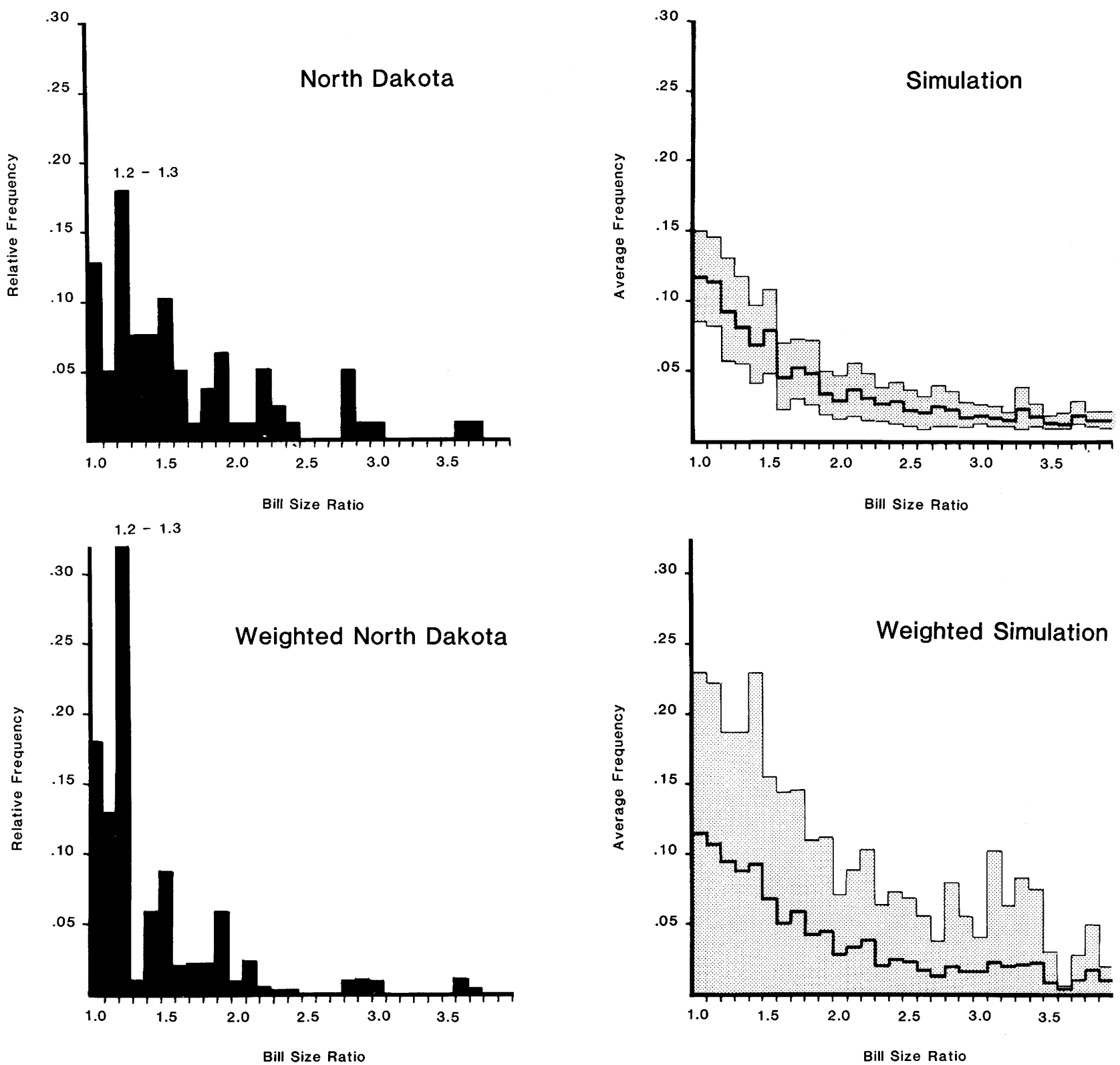

Fig. 4. Weighted and unweighted bill-size ratio distributions of two-species flocks from the 13 species in the North Dakota source pool compared to the sample distribution of two-species flocks from 100 source pools of 13 species each, drawn randomly from the global pool (the dark line represents the average frequency and the shaded area is the standard deviation). See text for details

Table 3. Observed bill-size ratio distributions (Real) compared to four source pools: global (G), Western Hemisphere (WH), North Dakota (ND), and weighted North Dakota (Wt. ND) ${ }^{a}$

\begin{tabular}{|c|c|c|c|c|c|c|c|c|c|}
\hline \multirow[b]{3}{*}{ Flock Size } & \multirow[b]{3}{*}{ Ratio } & \multicolumn{8}{|c|}{ Source Pool Comparisons } \\
\hline & & \multicolumn{2}{|l|}{ Real-G } & \multicolumn{2}{|c|}{ Real-WH } & \multicolumn{2}{|c|}{ Real-ND } & \multicolumn{2}{|c|}{ Real-Wt.ND } \\
\hline & & $\mathrm{D}$ & $P$ & $\mathrm{D}$ & $P$ & $\mathrm{D}$ & $P$ & $\mathrm{D}$ & $P$ \\
\hline 2-Species & $\mathrm{Sp} 1 / \mathrm{Sp} 2$ & 0.5078 & 0.01 & 0.4931 & 0.01 & 0.4390 & 0.01 & 0.1800 & NS \\
\hline 3-Species & $\begin{array}{l}\text { Sp1/Sp2 } \\
\text { Sp2/Sp3 }\end{array}$ & $\begin{array}{l}0.3130 \\
0.3920\end{array}$ & $\begin{array}{l}0.01 \\
0.01\end{array}$ & $\begin{array}{l}0.3180 \\
0.3480\end{array}$ & $\begin{array}{l}0.01 \\
0.01\end{array}$ & $\begin{array}{l}0.2714 \\
0.2236\end{array}$ & $\begin{array}{l}0.01 \\
0.05\end{array}$ & $\begin{array}{l}0.1090 \\
0.2430\end{array}$ & $\begin{array}{l}\text { NS } \\
0.01\end{array}$ \\
\hline 4-Species & $\begin{array}{l}\text { Sp1/Sp2 } \\
\text { Sp2/Sp3 } \\
\text { Sp3/Sp4 }\end{array}$ & $\begin{array}{l}0.1610 \\
0.3290 \\
0.4380\end{array}$ & $\begin{array}{l}0.01 \\
0.01 \\
0.01\end{array}$ & $\begin{array}{l}0.2350 \\
0.3320 \\
0.3360\end{array}$ & $\begin{array}{l}0.01 \\
0.01 \\
0.01\end{array}$ & $\begin{array}{l}0.1765 \\
0.1816 \\
0.2174\end{array}$ & $\begin{array}{l}\text { NS } \\
\text { NS } \\
\text { NS }\end{array}$ & $\begin{array}{l}0.1427 \\
0.2430 \\
0.0874\end{array}$ & $\begin{array}{l}\text { NS } \\
0.05 \\
\text { NS }\end{array}$ \\
\hline
\end{tabular}

${ }^{\text {a }}$ All comparisons use Kolmogorov-Smirnov maximum difference, $\mathrm{D}$, of cumulative frequencies $(\mathrm{NS}=P>0.05)$ 

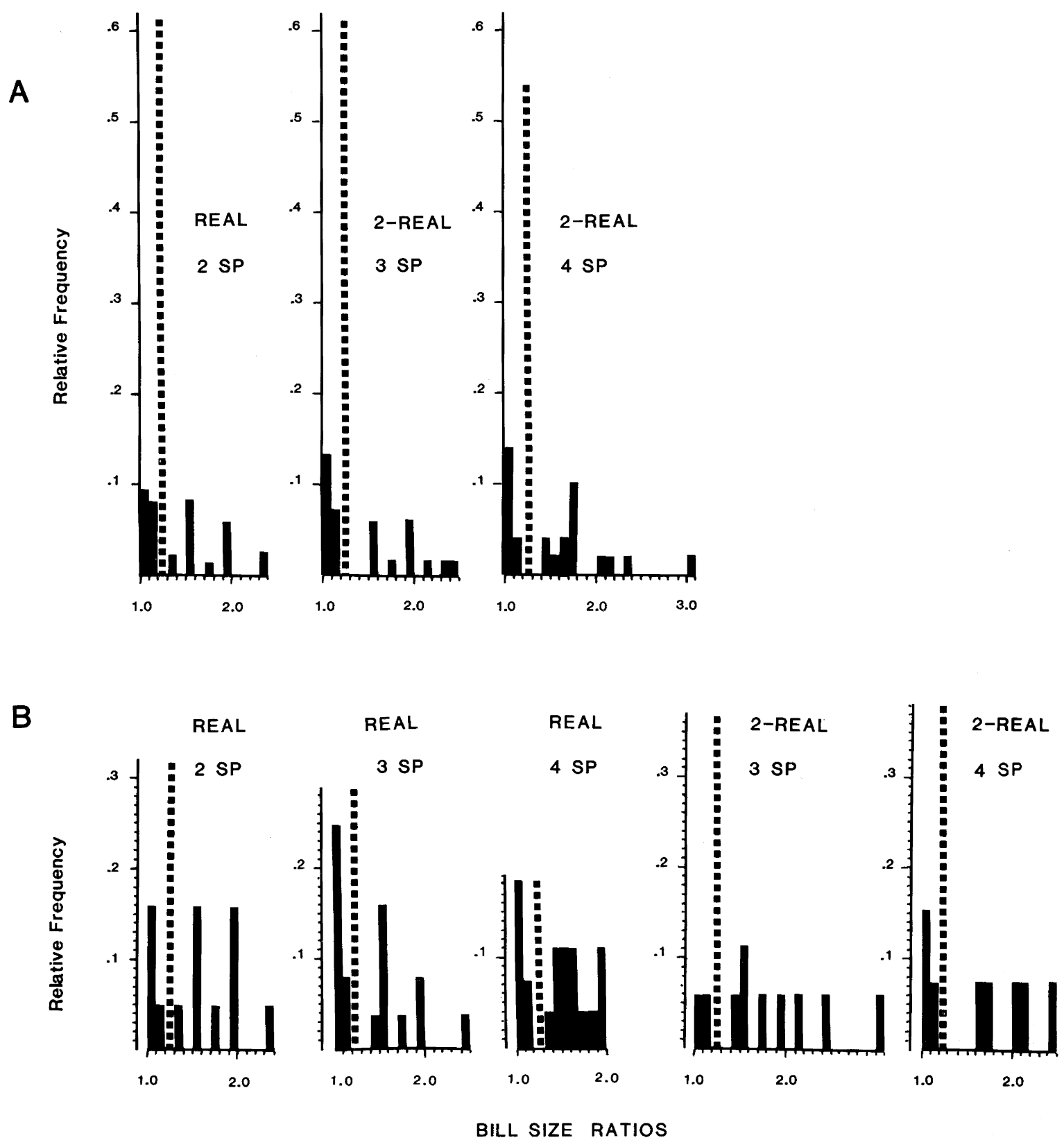

Fig. 5A. Bill-size ratio distributions from the two most abundant sandpiper species (2-Real distributions) observed in North Dakota in three- and four-species flocks were similar to the distribution from two-species flocks. B Ratio distributions from unique combinations. All repetitions are excluded. The dashed bar represents ratios, $r$, where $1.2 \leq r<1.3$

Table 4. Bill-size ratio distributions of two most abundant species from three- and four-species flocks (2-Real) compared to four source pools: global (G), Western Hemisphere (WH), North Dakota (ND), weighted North Dakota (Wt. ND), and observed (Real) ${ }^{\text {a }}$

\begin{tabular}{|c|c|c|c|c|c|c|c|c|c|c|c|}
\hline \multirow[b]{3}{*}{ Flock size } & \multirow[b]{3}{*}{ Ratio } & \multicolumn{10}{|c|}{ Source Pool Comparisons } \\
\hline & & \multicolumn{2}{|c|}{ 2-Real-G } & \multicolumn{2}{|c|}{ 2-Real-WH } & \multicolumn{2}{|c|}{ 2-Real-ND } & \multicolumn{2}{|c|}{ 2-Real-Wt. ND } & \multicolumn{2}{|c|}{ 2-Real-Real } \\
\hline & & $\mathrm{D}$ & $P$ & $\mathrm{D}$ & $P$ & $\mathrm{D}$ & $P$ & $\mathrm{D}$ & $P$ & & $P$ \\
\hline \multirow[t]{2}{*}{ 3-species } & $\mathrm{Sp} 1 / \mathrm{Sp} 2$ & 0.4530 & 0.01 & 0.4580 & 0.01 & 0.4114 & 0.01 & 0.2490 & 0.01 & 0.2110 & NS \\
\hline & $\mathrm{Sp} 2 / \mathrm{Sp} 3$ & 0.3560 & 0.05 & 0.3120 & 0.01 & 0.2132 & 0.05 & 0.4360 & 0.01 & 0.1930 & NS \\
\hline \multirow[t]{3}{*}{ 4-species } & $\mathrm{Sp} 1 / \mathrm{Sp} 2$ & 0.3910 & 0.01 & 0.4320 & 0.01 & 0.4392 & 0.01 & 0.3559 & 0.01 & 0.3080 & 0.05 \\
\hline & $\mathrm{Sp} 2 / \mathrm{Sp} 3$ & 0.3250 & 0.01 & 0.3280 & 0.01 & 0.2278 & 0.05 & 0.3682 & 0.01 & 0.3590 & 0.05 \\
\hline & $\mathrm{Sp} 3 / \mathrm{Sp} 4$ & 0.2950 & 0.01 & 0.2730 & 0.01 & 0.2656 & 0.05 & 0.5417 & 0.01 & 0.4870 & 0.01 \\
\hline
\end{tabular}

${ }^{\text {a }}$ All comparisons use Kolmogorov-Smirnov maximum difference, $\mathrm{D}$, of cumulative frequencies $(\mathrm{NS}=P>0.05)$ 
Table 5. The frequency of unique species combinations with billsize ratios of 1.2 to 1.3 in observed flocks

\begin{tabular}{lll}
\hline Species Combination & Ratio & Frequency \\
\hline White-rumped - Semipalmated & 1.24 & 0.588 \\
Pectoral - White-rumped & 1.20 & 0.115 \\
Lesser Yellowlegs - Pectoral & 1.28 & 0.107 \\
Pectoral - Baird's & 1.25 & 0.092 \\
Baird's - Least & 1.22 & 0.046 \\
White-rumped - Least & 1.26 & 0.038 \\
Sanderling - Semipalmated & 1.29 & 0.008 \\
Lesser Yellowlegs - Solitary & 1.22 & 0.008 \\
\hline
\end{tabular}

as it does in two- and three-species flocks (see Test 4), but is masked by the presence of a few individuals of intermediate-sized species within a flock.

\section{Test 6: Species combinations}

We asked if the pattern in ratio frequencies that we observed might be caused by repeated associations of a few species combinations. Ratios between 1.2 and 1.3 dominated the ratio distributions primarily but not entirely because White-rumped Sandpipers and Semipalmated Sandpipers were abundant and commonly associated. As many as eight unique observed species pairs had bill-size ratios ranging from 1.2 to 1.3 (Table 5). We eliminated repetitions in the flocks and considered only unique species combinations. This reduced the sample size considerably but did not change the shape of the distributions significantly when the unique combinations were compared to the observed ratio distributions (Kolmogorov-Smirnov Test, $P>0.05$ for all tests: Two-species flocks, $\mathrm{D}=0.2717$; Three-species flocks, Sp1/Sp2 D = 0.0935, Sp2/Sp3 D = 0.2250; Four-species flocks, Sp1/Sp2 D =0.1630, Sp2/Sp3 D =0.1494, Sp3/ $\mathrm{Sp} 4 \mathrm{D}=0.2124)$. Ratio distributions of unique combinations were unimodal and peaked in the range of 1.2 to 1.3 (Fig. 5 B). These results suggest that the size dependent pattern among migrants through North Dakota cannot be simply explained as an artifact caused by repeated associations of a few, very common species with this ratio.

Test 7: Size ratio constancy - within a flock

Schoener (1965) proposed that ratios within a guild increase with species size because individuals of larger species require a wider variety of prey sizes to survive. We tested this hypothesis and calculated the expected probability that ratios within a single flock increase with bill size for three- and four-species flocks. The expected probabilities were drawn from the global and North Dakota source pools and were indistinguishable from the observed probabilities drawn from actual flocks (Table 6). We conclude that while ratios tend to increase with the size of component species, the increase is no greater than one might expect given the unimodal, roughly log-normal underlying bill-size distribution.

\section{Test 8: Size ratio constancy - between flocks}

If species associate independently of size, each species added to a guild (flock) will tend to reduce the average size ratio and increase overall similarity within the guild (Tonkyn and Cole 1986). Here we compare median bill-size ratios for progressively larger flocks. If species associate independently of size, a decline in the median ratio of all distribu-
Table 6. Frequency of flocks with bill-size ratios increasing with bill size for observed flocks (REAL), and flocks generated from North Dakota (ND) and global (G) source pools

\begin{tabular}{|c|c|c|c|c|c|c|}
\hline \multirow[b]{3}{*}{ Flock size } & \multicolumn{6}{|c|}{ Source pool } \\
\hline & \multicolumn{2}{|c|}{ Real } & \multicolumn{2}{|l|}{ ND } & \multicolumn{2}{|l|}{ G } \\
\hline & $n$ & freq & $n$ & freq & $n$ & freq \\
\hline 3-species flocks & 57 & 0.51 & 286 & 0.62 & 1000 & 0.58 \\
\hline 4-species flocks & 39 & 0.28 & 715 & 0.26 & 1000 & 0.21 \\
\hline
\end{tabular}

Table 7. Medians of ratio distributions from global (G), Western Hemisphere (WH), North Dakota (ND), weighted North Dakota (Wt. ND), and observed (Real) ratio distributions for all ratio types and flock sizes

\begin{tabular}{lllllll}
\hline & & \multicolumn{2}{l}{ Source Pool } \\
\cline { 3 - 7 } Ratio & Size & G & WH & ND & Wt.ND & Real \\
\hline Sp1/Sp2 & 2 & 1.60 & 1.62 & 1.49 & 1.22 & 1.24 \\
& 3 & 1.52 & 1.57 & 1.45 & 1.26 & 1.24 \\
& 4 & 1.38 & 1.43 & 1.44 & 1.32 & 1.25 \\
Sp2/Sp3 & 3 & 1.34 & 1.31 & 1.26 & 1.20 & 1.24 \\
& 4 & 1.31 & 1.31 & 1.22 & 1.20 & 1.20 \\
Sp3/Sp4 & 4 & 1.27 & 1.23 & 1.22 & 1.20 & 1.20 \\
\hline
\end{tabular}

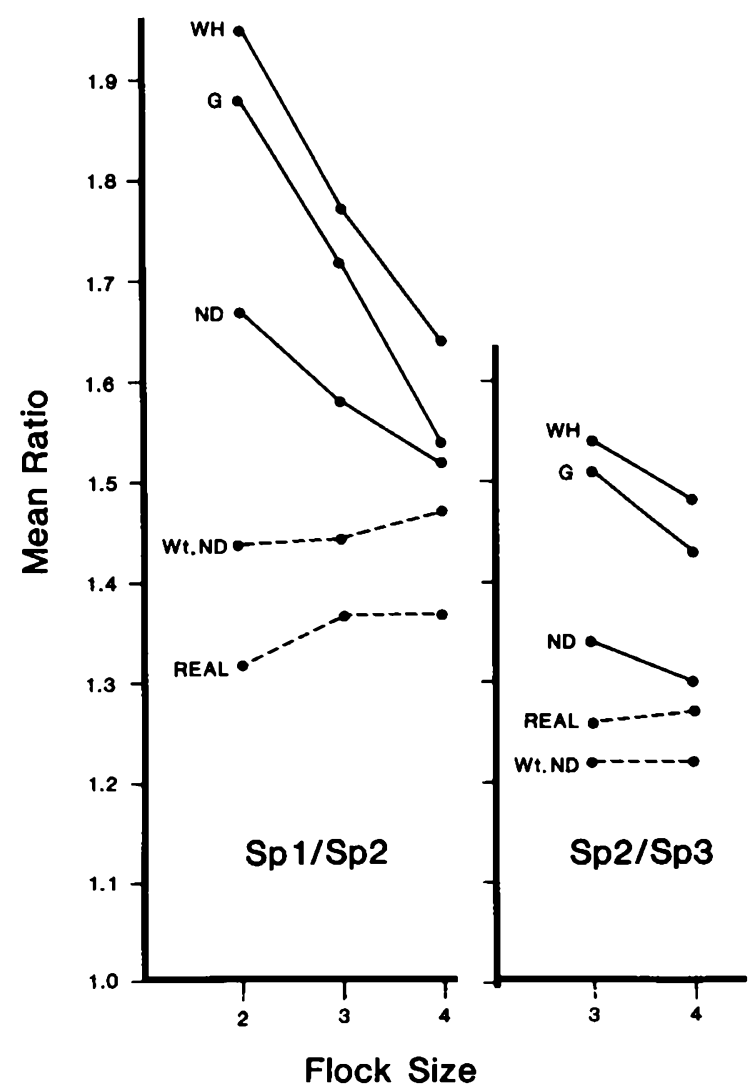

Fig. 6. Mean bill-size ratios of sandpipers from $\mathrm{Sp} 1 / \mathrm{Sp} 2$ and $\mathrm{Sp} 2 /$ Sp3 distributions for global $(G)$, Western Hemisphere $(W H)$, North Dakota $(N D)$, and weighted North Dakota (Wt.ND) source pools and observed $(R E A L)$ flocks 
Table 8. Sample size (n), mean (X), and variance $\left(\mathrm{s}^{2}\right)$ of global (A), North Dakota (B), and observed (C) ratio distributions with a $t$-test comparison of global and North Dakota means to observed means for 2-, 3-, and 4-species flocks

\begin{tabular}{|c|c|c|c|c|c|c|}
\hline \multicolumn{7}{|c|}{ A. Global Source Pool } \\
\hline \multirow[t]{3}{*}{ Parameter } & \multicolumn{6}{|c|}{ Flock Size and Ratio } \\
\hline & \multirow{2}{*}{$\begin{array}{l}\text { 2-Species } \\
\text { Sp1/Sp2 }\end{array}$} & \multicolumn{2}{|l|}{ 3-Species } & \multicolumn{3}{|l|}{ 4-Species } \\
\hline & & $\mathrm{Sp} 1 / \mathrm{Sp} 2$ & $\mathrm{Sp} 2 / \mathrm{Sp} 3$ & $\mathrm{Sp} 1 / \mathrm{Sp} 2$ & $\mathrm{Sp} 2 / \mathrm{Sp} 3$ & $\mathrm{Sp} 3 / \mathrm{Sp} 4$ \\
\hline $\mathrm{X}$ & 1.88 & 1.72 & 1.51 & 1.54 & 1.43 & 1.37 \\
\hline $\mathrm{s}^{2}$ & 0.70 & 0.43 & 0.26 & 0.28 & 0.19 & 0.13 \\
\hline$t$ & 6.06 & 3.92 & 3.67 & 2.02 & 2.36 & 3.79 \\
\hline$P$ & 0.001 & 0.001 & 0.001 & 0.05 & 0.02 & 0.001 \\
\hline
\end{tabular}

B. North Dakota Source Pool

\begin{tabular}{|c|c|c|c|c|c|c|}
\hline \multirow[t]{3}{*}{ Parameter } & \multicolumn{6}{|c|}{ Flock Size and Ratio } \\
\hline & \multirow{2}{*}{$\begin{array}{l}\text { 2-Species } \\
\text { Sp1/Sp2 }\end{array}$} & \multicolumn{2}{|l|}{ 3-Species } & \multicolumn{3}{|l|}{ 4-Species } \\
\hline & & $\mathrm{Sp} 1 / \mathrm{Sp} 2$ & $\mathrm{Sp} 2 / \mathrm{Sp} 3$ & $\mathrm{Sp} 1 / \mathrm{Sp} 2$ & $\mathrm{Sp} 2 / \mathrm{Sp} 3$ & $\mathrm{Sp} 3 / \mathrm{Sp} 4$ \\
\hline $\mathrm{X}$ & 1.67 & 1.58 & 1.34 & 1.54 & 1.43 & 1.37 \\
\hline $\mathrm{s}^{2}$ & 0.38 & 0.24 & 0.10 & 0.18 & 0.07 & 0.04 \\
\hline$t$ & 4.75 & 2.99 & 2.02 & 2.02 & 2.36 & 3.79 \\
\hline$P$ & 0.001 & 0.01 & 0.05 & 0.05 & 0.02 & 0.001 \\
\hline
\end{tabular}

C. Observed Flocks

\begin{tabular}{|c|c|c|c|c|c|c|}
\hline \multirow[t]{3}{*}{ Parameter } & \multicolumn{6}{|c|}{ Flock Size and Ratio } \\
\hline & \multirow{2}{*}{$\begin{array}{l}\text { 2-Species } \\
\text { Sp1/Sp2 }\end{array}$} & \multicolumn{2}{|l|}{ 3-Species } & \multicolumn{3}{|l|}{ 4-Species } \\
\hline & & $\mathrm{Sp} 1 / \mathrm{Sp} 2$ & $\mathrm{Sp} 2 / \mathrm{Sp} 3$ & $\mathrm{Sp} 1 / \mathrm{Sp} 2$ & $\mathrm{Sp} 2 / \mathrm{Sp} 3$ & $\mathrm{Sp} 3 / \mathrm{Sp} 4$ \\
\hline $\mathrm{X}$ & 1.32 & 1.37 & 1.26 & 1.37 & 1.27 & 1.15 \\
\hline $\mathrm{s}^{2}$ & 0.07 & 0.11 & 0.03 & 0.09 & 0.05 & 0.03 \\
\hline
\end{tabular}

tions can be expected because larger species have larger ratios given the underlying bill-size distribution (see Test 7). The test, then, asks if median ratios decline within ratio Sp1/Sp2 for two-, three-, and four-species flocks and continues to decline within ratio $\mathrm{Sp} 2 / \mathrm{Sp} 3$ for three- and fourspecies flocks, and with ratio $\mathrm{Sp} 3 / \mathrm{Sp} 4$ for four-species flocks (Table 7). According to Tonkyn and Cole (1986), a decline could indicate random species associations while constant or increasing ratios indicate nonrandom association.

We observed a significant decline in all six median ratios from global, Western Hemisphere, and North Dakota source pool distributions (Kendall rank correlation test, $P<0.01, P<0.05, P<0.05$, respectively). The results are consistent with the interpretation that flocks drawn from the source pools were random associations with respect to bill size. In contrast, median ratios from the weighted North Dakota source pool and observed flocks held constant or even increased for all six distributions (Kendall rank correlation test, $P>0.10)$.

The mean ratios show the same trend as the median ratios for each distribution (Fig. 6). We compared means from global and North Dakota expected ratio distributions with means from observed distributions using a $t$-test, which is robust when underlying distributions are not normal (Kendall and Stuart 1967; Box et al. 1978). In most comparisons, the observed mean ratios were significantly smaller than the expected mean ratios (Table 8). In addition, the variance in ratios decreased from global to North Dakota to observed distributions. The coefficient of variation also decreased (Table 9). These results suggest that ratios in observed flocks are more similar than expected, with fewer small ratios (less than 1.2) and fewer large ratios (1.3 and greater). In other words, sandpipers observed in mixed-species flocks were fairly uniformly separated in bill size by ratios of 1.2 to 1.3 (or a difference of 20 to $30 \%$ ).

\section{Discussion}

Ecologists have long believed that patterned size differences among species in a guild reflect interspecific competition (e.g., Huxley 1942; Lack 1944; Brown and Wilson 1956; see review by Carothers 1986). The correct procedure for determining size related patterns in observational data is controversial (Lewin 1982; Schoener 1982; Strong et al. 1984). Hutchinson (1959) argued that ecologically similar species will coexist if they differ in size by a minimum or constant amount, expressed as a ratio of larger to smaller 
Table 9. Coefficient of Variation (CV) comparisons of global, North Dakota, and observed ratio distributions for two-, three-, and four-species flocks where $\mathrm{CV}=(\mathrm{SD} / \mathrm{X})(\%)$

\begin{tabular}{|c|c|c|c|c|c|c|}
\hline \multirow[b]{3}{*}{ Source pool } & \multicolumn{6}{|c|}{ Flock size and ratio } \\
\hline & \multirow{2}{*}{$\begin{array}{l}\text { 2-Species } \\
\text { Sp1/Sp2 }\end{array}$} & \multicolumn{2}{|l|}{ 3-Species } & \multicolumn{3}{|l|}{ 4-Species } \\
\hline & & $\mathrm{Sp} 1 / \mathrm{Sp} 2$ & $\mathrm{Sp} 2 / \mathrm{Sp} 3$ & $\mathrm{Sp} 1 / \mathrm{Sp} 2$ & $\mathrm{Sp} 2 / \mathrm{Sp} 3$ & $\mathrm{Sp} 3 / \mathrm{Sp} 4$ \\
\hline Global & 44.6 & 38.4 & 34.0 & 34.1 & 30.1 & 26.0 \\
\hline North Dakota & 38.8 & 31.4 & 23.2 & 27.5 & 20.4 & 16.4 \\
\hline Observed & 19.7 & 24.5 & 13.6 & 21.5 & 17.4 & 13.9 \\
\hline
\end{tabular}

species, in the range of 1.2 to 1.4 . It is possible that size differences provide conservative evidence of competition because they reflect selective pressures over evolutionary time, whereas present-day competition between coexisting species is often difficult to demonstrate experimentally (Schoener 1982).

Recently, however, indirect evidence of biological interaction such as morphological differences has been questioned and even satirically labeled "ghosts of competition past" (Connell 1980). Empirical studies supporting Hutchinson's observation have been criticized for lacking statistical rigor because observed patterns were not tested against null hypotheses (Strong et al. 1979; Simberloff and Boecklen 1981).

In practice, null models are difficult to construct because the source pool of species used to develop them are seldom free of assumptions. Models used to test community-wide character differences in island archipelagoes (Strong et al. 1979) and size-ratio differences in small sets of closely related species (Simberloff and Boecklen 1981) have been criticized for not being independent of observation, in other words, not being truly null (Alatalo 1982; Case and Sidell 1983; Harvey et al. 1983; Colwell and Winkler 1984; Gilpin and Diamond 1984). Often null models depend on source pools that are reshuffled associations of species from a larger area constrained in a variety of ways to resemble observed species associations. The resulting null distributions quite possibly reflect aspects of biological interaction (cf., Colwell and Winkler 1984).

As others have discussed, conclusions drawn from null model comparisons depend on the source pools and assumptions used in the model (Schoener 1982; Harvey et al. 1983; Colwell and Winkler 1984; Gilpin and Diamond 1984; Schoener 1984; Tonkyn and Cole 1986; Schoener 1988). The North Dakota and weighted North Dakota pools were basically reshuffled combinations of species that were actually observed in flocks, and their ratio distributions were not random when compared with the sample distribution of ratios from 100, 13-species source pools drawn randomly from the global pool. The observed ratio distributions did not differ from the North Dakota distributions probably because the North Dakota source pools reflected Colwell and Winkler's (1984) Narcissus Effect, by which samples drawn from a post-competition source pool underestimate the role of competition when compared with observed associations.

The procedures we used to compare source pool subsets revealed patterns that might otherwise have gone undetected. The observed flocks had ratio distributions that were strongly unimodal with a predominance of species pairs with bill-size ratios of 1.2 to 1.3 . The pattern resulted be- cause this bill-size ratio was the most common among the sandpipers in the migration corridor through North Dakota. This changes the question to why are ratios of 1.2 to 1.3 so common among the sandpipers that migrate through North Dakota? The species in the migration corridor were not a random selection from the global pool of Arctic-nesting sandpipers or from those migrating through the Western Hemisphere. The distribution of bill-size ratios of the species in the migration corridor differed from the global and Western Hemisphere distribution as predicted by Tonkyn and Cole (1986) when size-related selection such as competition has influenced the species association.

The patterns we observed in bill-size ratios are consistent with the interpretation that some form of size-related selection such as interspecific competition over evolutionary time has influenced species occurrence and abundance in the migration corridor through North Dakota. In short, the ephemeral, mixed-species foraging flocks we observed in North Dakota were random mixes from a nonrandom pool.

Acknowledgments. This research was funded by the U.S. Fish and Wildlife Service through Northern Prairie Wildlife Research Center and by a James W. Wilke Fellowship for dissertation research to the first author from the Bell Museum of Natural History, University of Minnesota. We are pleased to acknowledge the significant contributions of W. Reid Goforth, Gary L. Krapu, Nathan R. Flesness, and Harrison B. Tordoff. The research effort was strengthened by excellent field assistants especially Michael Rabenberg, Riley Atkins, Charles W. Schaiffer, and Mavis Meyer. The manuscript benefited from comments by a number of helpful reviewers including Peter A. Abrams, Francesca J. Cuthbert, Frank McKinney, Thomas W. Schoener, Catherine A. Toft, and Harrison B. Tordoff.

Appendix A. Species included in the analysis are listed with source pool and mean bill size. The North Dakota source pool (3) is a subset of the Western Hemisphere pool (2 and 3) which is a subset of the global pool $(1,2$, and 3$)$. Bill sizes are means of geographic and sexual differences listed in Prater et al. 1977, except those marked $\left(^{*}\right)$ which are means from specimens collected in North Dakota.

\begin{tabular}{lll}
\hline Species & $\begin{array}{l}\text { Source } \\
\text { pool }\end{array}$ & $\begin{array}{l}\text { Bill size } \\
\text { mean } \\
(\mathrm{mm})\end{array}$ \\
\hline 1. Bar-tailed Godwit, Limosa lapponica & 2 & 93 \\
2. Whimbrel, Numenius phaeopus & 2 & 85.4 \\
3. Hudsonian Godwit, Limosa haemastica & 2 & 82 \\
4. Bristle-thighed Curlew, Numenius & 2 & 82 \\
$\quad$ tahitiensis & 2 & 66.8
\end{tabular}




\begin{tabular}{lll}
\hline Species & $\begin{array}{l}\text { Source } \\
\text { pool }\end{array}$ & $\begin{array}{l}\text { Bill size } \\
\text { mean } \\
(\mathrm{mm})\end{array}$
\end{tabular}

6. Long-billed Dowitcher, Limnodromus scolopaceus

7. Great Snipe, Gallinago media

8. Pin-tailed Snipe, Gallinago stenura

9. Short-billed Dowitcher, Limnodromus griseus

10. Spotted Redshank, Tringa erythropus

11. Common Greenshank, Tringa nebularia

12. Greater Yellowlegs, Tringa melanoleuca

13. Eskimo, Curlew, Numenius borealis

14. Terek Sandpiper, Xenus cinereus

15. Little Whimbrel, Numenius minutus

16. Great Knot, Calidris tenuirostris

17. Stilt Sandpiper, Calidris himantopus

18. Jack Snipe, Lymnocryptes minimus

19. Wandering Tattler, Heteroscelus incanus

20. Curlew Sandpiper, Calidris ferruginea

21. Grey-tailed Tattler, Heteroscelus brevipes

22. Dunlin, Calidris alpina

23. Lesser Yellowlegs, Tringa flavipes

24. Green Sandpiper, Tringa ochropus

25. Red Knot, Calidris canutus

26. Ruff, Philomachus pugnax

27. Broad-billed Sandpiper, Limicola falcinellus

28. Solitary Sandpiper, Tringa solitaria

29. Purple Sandpiper, Calidris maritima

30. Rock Sandpiper, Calidris ptilocnemis

31. Wood Sandpiper, Tringa glareola

32. Pectoral Sandpiper, Calidris melanotos

33. Sharp-tailed Sandpiper, Calidris acuminata

34. Common Sandpiper, Actitis hypoleucos

35. Sanderling, Calidris alba

36. Western Sandpiper, Calidris mauri

37. Surfbird, Aphriza virgata

38. White-rumped Sandpiper, Calidris fuscicollis

39. Black Turnstone, Arenaria melanocephala

40. Baird's Sandpiper, Calidris bairdii

41. Grey Phalarope, Phalaropus fulicarius

42. Ruddy Turnstone, Arenaria interpres

43. Spoonbill Sandpiper, Eurynorhynchus pygmeus

44. Red-necked Phalarope, Phalaropus lobatus

45. Buff-breasted Sandpiper, Tryngites subruficollis

46. Semipalmated Sandpiper, Calidris pusilla

47. Least Sandpiper, Calidris minutilla

48. Little Stint, Calidris minuta

49. Long-toed Stint, Calidris subminuta

50. Rufous-necked Stint, Calidris ruficollis

51. Temminck's Stint, Calidris temminckii
$69.6^{*}$

64.4

62.7

59.6

58.2

54.5

54.2

53.2

47.1

44

43.2

$41.4^{*}$

40.5

39.1

37.7

37.7

$37.7^{*}$

36.4 *

34.4

33.4

33.0

31.8

29.9

29.5

29.4

28.7

$28.5^{*}$

24.8

24.8

24.6

24.6

24.0

$23.7^{*}$

23.2

$22.8^{*}$

22.6

22.0

21.4

21.4

19.3

$19.1^{*}$

18.8 *

18.4

18.0

17.5

16.9

Appendix B. Species composition of observed two-, three-, and four-species flocks. Species are sorted by bill size and numbered as in Appendix A.

Two-species flocks: $6-23,12-32,12-40,17-38,22-38,23-32,23-40$, $23-46,28-40,32-40,32-47,35-40,35-46,38-40,38-46,38-47$, 40-46, 40-47, 46-47.

Three-species flocks: 6-23-32, 6-23-40, 6-32-40, 6-32-47, 17-22-38, $17-23-38, \quad 17-23-46, \quad 17-32-46,17-38-46,22-38-46,22-38-47$, 23-28-32, 23-32-40, 23-32-46, 23-32-47, 23-38-46, 23-28-47, $23-40-46, \quad 32-38-46,32-38-47,32-46-47,35-38-40,35-38-46$, $36-40-46,38-40-46,38-40-47,38-46-47,40-46-47$.

Four-species flocks: 6-17-23-46, 6-22-38-40, 6-23-32-40, 6-23-40-47, $12-22-46-47, \quad 12-23-32-40, \quad 17-22-38-40, \quad 17-23-38-40$, $17-32-38-40, \quad 17-35-38-40, \quad 22-23-40-32, \quad 22-32-38-40$, $22-38-40-46, \quad 23-32-38-40, \quad 32-38-40-46, \quad 32-35-38-40$, $35-38-40-46$.

\section{References}

Alatalo RV (1982) Bird species distributions in the Galapagos and other archipelagoes: competition or chance? Ecology 63:881-887

Ashkenazie S, Safriel UN (1979) Time-energy budget of the Semipalmated Sandpiper Calidris pusilla at Barrow, Alaska. Ecology 60:783-799

Box GEP, Hunter WG, Hunter JS (1978) Statistics for experimenters: an introduction to design, data analysis, and model building. John Wiley and Sons, New York

Brown WL, Wilson EO (1956) Character displacement. Syst Zool 5:49-64

Carothers JH (1986) Homage to Huxley: on the conceptual origin of minimum size ratios among competing species. Am Nat $128: 440-442$

Case TJ, Sidell R (1983) Pattern and chance in the structure of model and natural communities. Evolution 37:832-849

Colwell RK, Winkler DW (1984) A null model for null models in biogeography. In: Strong DR, Simberloff D, Abele LG, Thistle AB (eds) Ecological communities: conceptual issues and the evidence. Princeton University Press, Princeton, New Jersey, pp 344-359

Connell JH (1980) Diversity and the coevolution of competitors, or the ghost of competition past. Oikos 35:131-138

Connor EF, Simberloff D (1979) The assembly of species communities: chance or competition? Ecology 60:1132-1140

Eadie JM, Broekhoven L, Colgan P (1987) Size ratios and artifacts: Hutchinson's rule revisited. Am Nat 129:1-17

Gilpin ME, Diamond JM (1984) Are species co-occurrences on islands non-random and are null hypotheses useful in community ecology? In: Strong DR, Simberloff D, Abele LG and Thistle AB (eds) Ecological communities: conceptual issues and the evidence. Princeton University Press, Princeton, New Jersey, pp 297-331

Grant PR (1967) Bill length variability in birds of the Tres Marias Islands, Mexico. Can J Zool 45:805-815

Harvey PA, Colwell RK, Silvertown JW, May RM (1983) Null models in ecology. Annu Rev Ecol Syst 14:189-211

Hayman P, Marchant J, Prater T (1986) Shorebirds: an identification guide to the waders of the world. Houghton Mifflin Company. Boston, Massachusetts

Hespenheide HA (1973) Ecological inferences from morphological data. Annu Rev Ecol Syst 4:213-229

Holmes RT, Pitelka FA (1968) Food overlap among coexisting sandpipers on northern Alaskan tundra. Syst Zool 17:305-318

Hutchinson GE (1959) Homage to Santa Rosalia or why are there so many kinds of animals? Am Nat 93:145-159

Huxley J (1942) Evolution: the modern synthesis. Harper, New York

Kendall MG, Stuart A (1967) The advanced theory of statistics, vol 2. Hafner Publishing Company, New York

Lack D (1944) Ecological aspects of species formation in passerine birds. Ibis $86: 260-286$

Lewin R (1982) Santa Rosalia was a goat. Science 221 :636-639

MacLean SF (1969) Ecological determinants of species diversity of Arctic sandpipers near Barrow, Alaska. Unpublished Ph.D. Thesis, University of California, Berkeley, California

Myers JP (1981) Cross-seasonal interactions in the evolution of sandpiper social systems. Behav Ecol Sociobiol 8:195-202

Pianka ER (1974) Niche overlap and diffuse competition. Proc Natl Acad Sci USA 71:2141-2145

Prater AJ, Marchant JH, Vuorinen J (1977) Guide to the identification and ageing of holarctic waders. British Trust for Ornithol- 
ogy, Field Guild 17. Beech Grove, Tring, Hertfordshire, Great Britain

Recher HF (1966) Some aspects of the ecology of migrant shorebirds. Ecology 47:393-407

Recher HF, Recher JA (1969) Some aspects of the ecology of migrant shorebirds. II. Aggression. Wilson Bull 81:140-154

Schneider DC, Harrington BA (1981) Timing of shorebird migration in relation to prey depletion. Auk 98:801-811

Schoener TW (1965) The evolution of bill size differences among sympatric species of birds. Evolution 19:189-213

Schoener TW (1982) The controversy over interspecific competition. Am Sci 70:586-595

Schoener TW (1984) Size differences among sympatric, bird-eating hawks: a worldwide survey. In: Strong DR, Simberloff D, Abele LG, and Thistle AB (eds) Ecological communities: conceptual issues and the evidence. Princeton University Press, Princeton, New Jersey, pp 254-281

Schoener TW (1986) Resource Partitioning. In: Kikkawa J, Anderson DJ (eds) Resource Partitioning. Blackwell Scientific Publications, Melbourne

Schoener TW (1988) Testing for nonrandomness in sizes and habitats of West Indian lizards: choice of species pool affects conclusions from null models. Evol Ecology (in press)
Simberloff D, Boecklen W (1981) Santa Rosalia reconsidered. Evolution 35:1206-1228

Sokal RR, Rohlf FJ (1981) Biometry. W.H. Freeman and Co., San Francisco, California

Stewart RE, Kantrud HA (1971) Classification of natural ponds and lakes in the glaciated prairie region. Resource Publication 92, US Fish and Wildlife Service

Strong DR, Simberloff D, Abele LG, Thistle AB (1984) Ecological communities: conceptual issues and the evidence. Princeton University Press, Princeton, New Jersey

Strong DR, Szyska LA, Simberloff D (1979) Tests of communitywide character displacement against null hypotheses. Evolution 33:897-913

Tonkyn DW, Cole BJ (1986) The statistical analysis of size ratios. Am Nat 128:66-81

Wiens JA (1984) On understanding a non-equilibrium world: myth and reality in community patterns and processes. In: Strong DR, Simberloff D, Abele LG, Thistle AB (eds) Ecological communities: conceptual issues and the evidence. Princeton University Press, Princeton, New Jersey, pp 439-457

Received March 14, 1988 